\title{
Fluorescence quenching of DMB by aniline in benzene-acetonitrile mixture
}

\author{
Ashok H. Sidarai ${ }^{a}$, Vani R. Desai ${ }^{a}$, Shirajahammad M. Hunagund ${ }^{a}$, \\ Mahantesha Basanagouda $^{b}$, Jagadish S. Kadadevarmath ${ }^{a}$ \\ ${ }^{a}$ Department of Studies in Physics, Karnatak University, Dharwad-580003, Karnataka, India \\ ${ }^{b}$ P. G. Department of Studies in Chemistry, K. L. E. Society's P. C. Jabin Science College, Hubli- \\ 580031, Karnataka, India \\ ${ }^{*}$ Corresponding email: ashok_sidarai@rediffmail.com
}

\begin{abstract}
Keywords: Fluorescence quenching, sphere of action static quenching model, finite sink approximation model.
\end{abstract}

\begin{abstract}
The fluorescence quenching of coumarin dye namely 4-(2, 6-dibromo-4-methylphenoxymethyl)-benzo[h]chromen-2-one [DMB] has been studied by aniline, in a different solvent mixture of benzene (BN) and acetonitrile (AN) at room temperature. The quenching is found to be appreciable and shows positive deviation from linearity in the Stern-Volmer $(\mathrm{S}-\mathrm{V})$ plots for all the solvent mixtures. The various rate parameters responsible for fluorescence quenching have been determined using a sphere of action static quenching model and finite sink approximation model. The magnitudes of these rate parameters indicate that positive deviation in the S-V plot is due to both static and dynamic quenching processes.
\end{abstract}

\section{Introduction}

Derivatives of coumarin are well-known for their photochemical and photophysical properties, as well as for their interesting second-order nonlinearities [1]. They are extensively studied due to their widespread industrial use as dye lasers [2]. Now a day, there has been drive to synthesize coumarin-based organic dyes for use in high-efficiency dye-sensitized solar cells (DSCs) [3-4]. Coumarin and its derivatives have attracted significant interest in pharmaceutical research areas such as anti-inflammatory, hepatoprotective, antiviral, anticarcinogenic and anticoagulant activities [5-6].

The fluorescence quenching of organic molecules in solution by various quenchers like aniline, carbon tetrachloride, halides ions, ethyltriocarbonate, CdSe nanoparticles, oxygen etc has been studied by several investigators [7-12]. In all most all cases the experimental results follow the linear Stern-Volmer equation given by

$$
\frac{I_{0}}{I}=1+K_{S V}[Q]
$$

$\mathrm{K}_{\mathrm{SV}}=\mathrm{k}_{\mathrm{q}} \tau_{0}$ called S-V constant. Where $\mathrm{I}_{0}, \mathrm{I}, k_{q}, \tau_{0}$ and $[Q]$ are the fluorescence intensities in the absence and presence of the quencher, bimolecular quenching rate parameter, lifetime of the excited solute molecule in the absence of quencher and quencher concentration respectively. But in few cases, it has been observed that the experimental results show positive deviation from a linear $\mathrm{S}-\mathrm{V}$ relation [13-15]. This positive deviation was attribute to various processes like singlet to triplet excitation, static and dynamic quenching, the formation of charge transfer complexes both at the ground and excited states. Apart from this, the polarity of the solvent medium and the range of quencher concentration are also except to play a part in this mechanism.

In the present work, we have studied the steady state fluorescence quenching of the newly synthesised coumarin derivative DMB using aniline as a quencher in a different mixture of benzene and acetonitrile at room temperature. The various rate constants responsible for fluorescence quenching mechanisms have been estimated using a sphere of action static quenching model and a finite sink approximation model. 


\section{Materials and methods}

The coumarin dye DMB was synthesized according to the literature [16] and its molecular structure is shown in Fig. 1. The solvents were obtained from the SD-fine chemical limited Indian. The quencher aniline was double distilled and tested for its purity before use. The solutions were prepared using benzene and acetonitrile in different proportions by volume with a fixed solute concentration of $1 \times 10^{-5} \mathrm{M} / \mathrm{L}$ and quencher concentrations were varied from $0.02-0.10 \mathrm{M} / \mathrm{L}$. The absorption spectra, fluorescence spectra and fluorescence lifetime were recorded using UV/visible spectrophotometer [model: Hitachi U-3310, Japan], fluorescence spectrophotometer [model: Hitachi F-7000, Japan] and time-correlated single photon counting technique (TCSPC) [model: ISS90021] respectively. All these spectroscopic measurements were carried out at room temperature $[300 \mathrm{~K}]$.<smiles>Cc1cc(Br)c(OCc2cc(=O)oc3c2ccc2ccccc23)c(Br)c1</smiles>

Fig. 1 Molecular structure of DMB.

\section{Results and discussion}

Initially, the fluorescence intensity $\mathrm{I}_{0}$ was measured without quencher concentration and then the fluorescence intensity I was measured at different quencher concentrations in a fixed solute concentration. Practical values were reproducible within $5 \%$ of the experimental errors. The S-V plots $\mathrm{I}_{0} / \mathrm{I}$ versus [Q] for $\mathrm{DMB}$ are shown in Fig. 2 were found to be non-linear, shows positive deviation, it may be concluded that the quenching is not purely collisional in other word's it may be due to either the ground state complex formation or static quenching process.

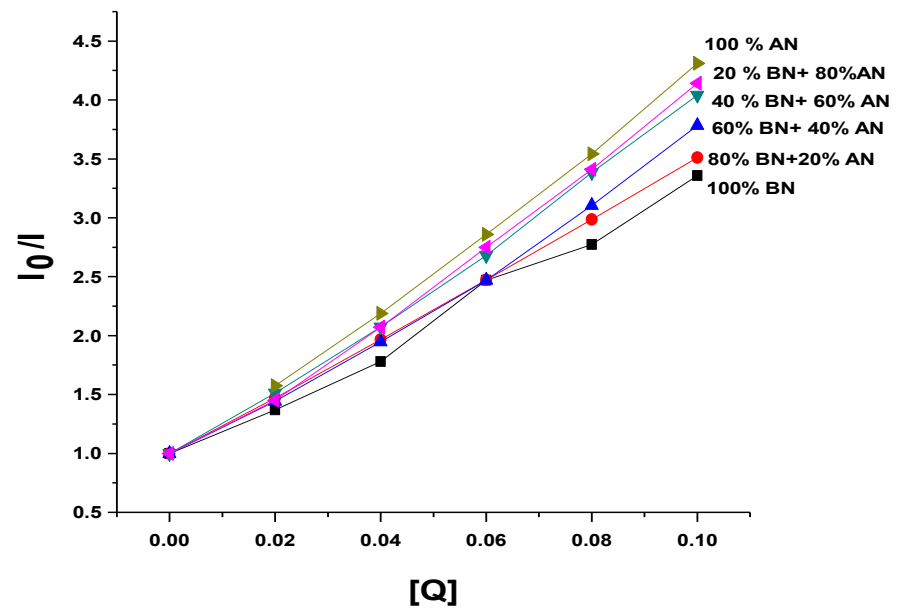

Fig. 2 S-V plots for DMB.

The deviations from the linearity of S-V plots were explained using the sphere of action static quenching model. According to this, the static quenching was explained by introducing an additional factor $W$ in the linear $\mathrm{S}-\mathrm{V}$ plots and the fraction $\mathrm{W}$ depends on the quencher concentration [Q]. 


$$
\left[1-\left(\mathrm{I} / \mathrm{I}_{0}\right)\right] /[\mathrm{Q}]=\mathrm{K}_{\mathrm{SV}}\left(\mathrm{I} / \mathrm{I}_{0}\right)+(1-\mathrm{W}) /[\mathrm{Q}]
$$

The graph of $\left[1-\left(\mathrm{I} / \mathrm{I}_{0}\right)\right] /[\mathrm{Q}]$ versus $\left(\mathrm{I} / \mathrm{I}_{0}\right)$ for $\mathrm{DMB}$ are shown in Fig. 3, from these graphs we can easily estimate the values of $\mathrm{K}_{\mathrm{sv}}$ and $\mathrm{W}$ by least-square fit method.

Frank and Wawilow [17] have suggested that the instantaneous quenching results at the instances in a randomly distributed system when a quencher happens to reside within a sphere of action with volume of $\frac{V}{N^{\prime}}$ and kinetic distance r.

i.e. $\quad \frac{V}{N^{\prime}}=\frac{4}{3} \pi \mathrm{r}^{3}$

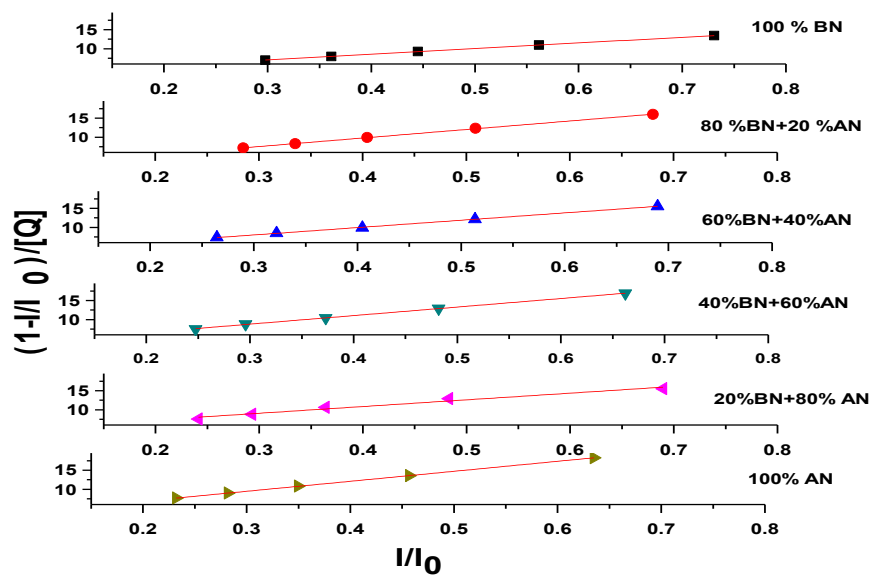

Fig. 3 The plots of $\left[1-\left(\mathrm{I} / \mathrm{I}_{0}\right)\right] /[\mathrm{Q}]$ versus $\left(\mathrm{I} / \mathrm{I}_{0}\right)$ in different solvent mixtures $(\mathrm{BN}+\mathrm{AN})$.

The dielectric constant of solvent mixtures and various quenching rate parameters calculated from sphere of action static quenching models namely S-V constant $\left(\mathrm{K}_{\mathrm{sv}}\right)$ bimolecular quenching rate parameters $\left(\mathrm{k}_{\mathrm{q}}\right)$, range $(\mathrm{W})$, static quenching constant $(\mathrm{V})$ and kinetic distance $(\mathrm{r})$ for DMB in different solvent mixtures are shown in Table 1 . The radii of the solute $\left(R_{S}\right)$ and a quencher $\left(R_{Q}\right)$ were estimated by Edward method [18] and are given at the bottom of Table 1, from these values the sum of the molecular radii $\mathrm{R}\left(\mathrm{R}_{\mathrm{S}}+\mathrm{R}_{\mathrm{Q}}\right)$ is determined, and it is referred as encounter distance. These values are compared with the values of ' $r$ ' in order to verify whether the reaction is due to sphere of action static quenching model. From Table 1 we observed that values of kinetic distances $r$ are greater than the encounter distances R. Therefore, according to Andre et al. [19] and Zeng et al. [20] the static effect takes place irrespective of ground state complex formation, provided reactions are limited by diffusion indicating the sphere of action static models holds good.

Table 1. The dielectric constant of solvent mixture and various fluorescence quenching rate parameters calculated from the sphere of action static quenching model.

\begin{tabular}{|c|c|c|c|c|c|c|c|c|}
\hline Molecule & \multicolumn{2}{|c|}{$\begin{array}{c}\text { Solvent } \\
\text { mixture }\end{array}$} & $\begin{array}{c}\text { Dielectric } \\
\text { constant }\end{array}$ & $\begin{array}{c}\mathrm{K}_{\mathrm{SV}} \\
\left(\mathrm{m}^{-1}\right)\end{array}$ & $\begin{array}{c}\mathrm{k}_{\mathrm{q}} \\
\left(\mathrm{m}^{-1} \mathrm{~s}^{-1}\right)\end{array}$ & Range W & $\begin{array}{c}\mathrm{V} \\
\left(\mathrm{mol}^{-1} \mathrm{dm}^{3}\right)\end{array}$ & $\begin{array}{c}\mathrm{r} \\
(\mathrm{A})\end{array}$ \\
\cline { 2 - 9 } BN\% & AN\% & & & & & & \\
\hline \multirow{5}{*}{ DMB } & 100 & 00 & 2.284 & 14.599 & 1.339 & $0.726-0.945$ & 3.253 & 10.88 \\
\cline { 2 - 9 } & 80 & 20 & 10.67 & 18.309 & 1.679 & $0.769-0.953$ & 2.689 & 10.20 \\
\cline { 2 - 9 } & 60 & 40 & 15.18 & 21.008 & 1.927 & $0.776-0.955$ & 2.588 & 10.08 \\
\cline { 2 - 9 } & 40 & 60 & 24.30 & 22.415 & 2.056 & $0.792-0.958$ & 2.488 & 9.95 \\
\cline { 2 - 9 } & 20 & 80 & 30.46 & 24.684 & 2.264 & $0.846-0.964$ & 1.688 & 8.74 \\
\cline { 2 - 9 } & 00 & 100 & 37.12 & 26.273 & 2.410 & $0.841-0.968$ & 1.748 & 8.84 \\
\hline
\end{tabular}

$\mathrm{R}_{\mathrm{S}}=4.2819 \mathrm{~A}^{\circ}, \mathrm{R}_{\mathrm{Q}}=2.840 \mathrm{~A}^{\circ}, \tau_{0}=1.09 \mathrm{~ns}$.

In order to find out whether the reactions are diffusion limited, we need to use the finite sink approximation model [21].

$\mathrm{K}_{\mathrm{SV}}{ }^{-1}=\mathrm{K}_{\mathrm{SV}}{ }^{0-1}-\left[\left(2 \pi \mathrm{N}^{\prime}\right)^{1 / 3} / 4 \pi \mathrm{N}^{\prime} \mathrm{D} \tau_{0}\right] \mathrm{Q}^{1 / 3}$

This model helps us to estimate independently the mutual diffusion coefficient $(D)$ and distance parameter $R^{\prime}$. Fig. 4 shows the graph of $K_{S V}^{-1}$ versus [Q] ${ }^{1 / 3}$, which are linear with a negative slope for all the solvent mixtures. The mutual diffusion coefficient (D) becomes directly 
accessible from the slope and $K_{s v}^{0}$ is obtained from the intercept of the graph of $K_{S V}^{-1} \mathrm{~V} / \mathrm{s}[\mathrm{Q}]^{1 / 3}$ and these values are given in Table 2. From $K_{s v}^{0}$, it is possible to find out the distance parameter R'. The value of $4 \pi N^{\prime} D R^{\prime}$ are estimated using the experimentally determined values of $R^{\prime}$ and $D$ are shown in Table 2. According to Joshi et al. [22] the bimolecular reactions are said to be diffusion limited if the values of $\mathrm{k}_{\mathrm{q}}$ are greater than $4 \pi \mathrm{N}^{\prime} \mathrm{DR}$ '. From the Table 2, it can be seen that for all the solvent mixtures the values of $\mathrm{k}_{\mathrm{q}}$ are greater than $4 \pi \mathrm{N}^{\prime} \mathrm{DR}$, which is an excepted result for diffusion limited reaction.

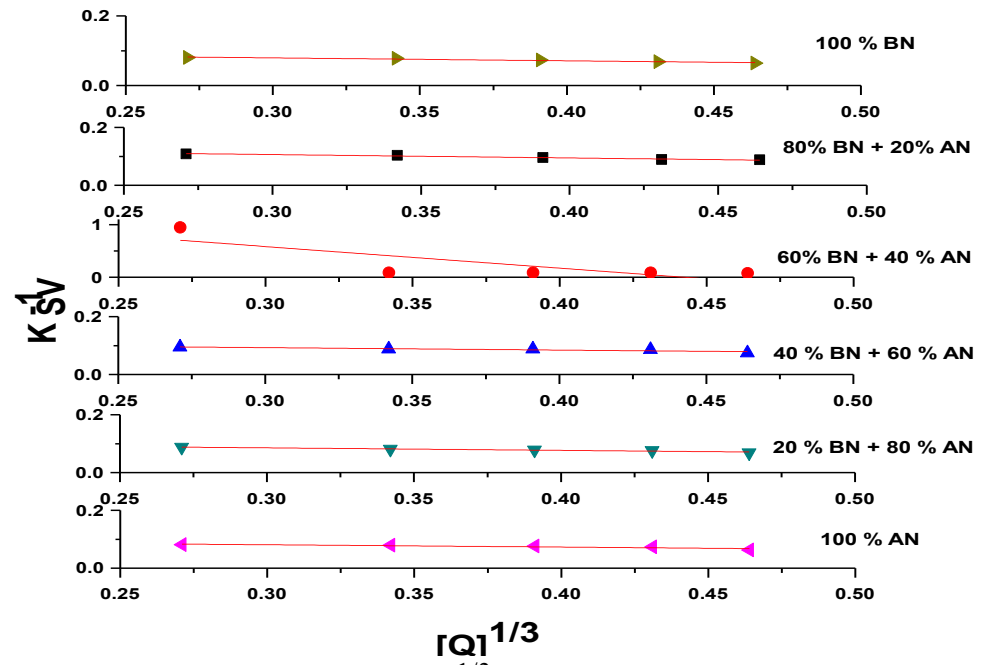

Fig. 4 The plots of $K_{S V}^{-1}$ versus $[\mathrm{Q}]^{1 / 3}$ in different solvent mixtures $(\mathrm{BN}+\mathrm{AN})$.

Table 2. The various quenching rate parameters calculated from finite sink approximation model.

\begin{tabular}{|c|c|c|c|c|c|c|c|}
\hline \multirow[t]{2}{*}{ Molecule } & \multicolumn{2}{|c|}{ Solvent mixture } & \multirow{2}{*}{$\begin{array}{c}K_{s v}^{o} \\
\left(\mathrm{dm}^{3} \mathrm{~mol}^{-1}\right)\end{array}$} & \multirow{2}{*}{$\begin{array}{l}D \times 10^{5} \\
\left(\mathrm{~cm}^{2} \mathrm{~s}^{-1}\right)\end{array}$} & \multirow{2}{*}{$\begin{array}{l}R^{\prime} \\
(\AA)\end{array}$} & \multirow{2}{*}{$\begin{array}{c}4 \pi N^{\prime} R^{\prime} D \times 10^{-10} \\
\left(\mathrm{~m}^{-1} \mathrm{~s}^{-1}\right)\end{array}$} & \multirow{2}{*}{$\begin{array}{l}k_{q} \times 10^{-10} \\
\left(\mathrm{~m}^{1} \mathrm{~s}^{-1}\right)\end{array}$} \\
\hline & $\mathrm{BN}(\%)$ & AN (\%) & & & & & \\
\hline \multirow{6}{*}{ DMB } & 100 & 00 & 8.4033 & 1.9328 & 5.040 & 0.07521 & 0.5421 \\
\hline & 80 & 20 & 8.5540 & 2.1842 & 4.538 & 0.07503 & 0.6979 \\
\hline & 60 & 40 & 8.1830 & 1.8310 & 5.177 & 0.07170 & 0.7063 \\
\hline & 40 & 60 & 8.9440 & 2.0638 & 5.022 & 0.07844 & 0.7546 \\
\hline & 20 & 80 & 10.619 & 3.8770 & 3.173 & 0.09313 & 0.8583 \\
\hline & 00 & 100 & 10.245 & 2.8860 & 4.115 & 0.08990 & 0.8991 \\
\hline
\end{tabular}

\section{Conclusions}

From the above discussion we observed that

(1) The S-V plots show the positive deviation leading to high value of $k_{q}$ it indicates the efficiency of fluorescence quenching.

(2) The dependence of S-V constant on dielectric constant of the solvent mixture indicates the possibility of solvent molecule composition around the fluorescent.

(3) The value of quenching rate parameter $k_{\mathrm{q}}$ increases with increase in dielectric constant of the solvent mixture and it is suggesting the charge transfer character of the excited state complex.

(4) Finite sink approximation model helps to recover R' and D directly from the plots of $\mathrm{K}_{\mathrm{SV}}{ }^{-1}$ versus $[\mathrm{Q}]^{1 / 3}$.

(5) The value of $k_{\mathrm{q}}$ is greater than $4 \pi \mathrm{N}^{\prime} \mathrm{R}$ 'D in all the solvent mixtures.

From the above facts, we conclued that quenching phenomenon in DMB is diffusion limited and both static and dynamic quenching processes are playing a role.

\section{Acknowledgements}

The authors (VRD and SMH) acknowledge the financial support under UGC-UPE fellowship from Karanatak University Dharwad. Authors are grateful to the technical staff of USIC, Karnatak University Dharwad for recording absorption spectra, fluorescence spectra and fluorescence lifetime measurements. 


\section{References}

[1] Mortazavi M. A et al. Second-order nonlinear optical properties of poled Coumaromethacrylate copolymers, Appl. Phys. B: Lasers Opt, 53 (1991) 287-295.

[2] Duarte F. J, Hillman L. W, Dye laser principles, with applications, Academic Press Inc.: San Diego, CA, 1990.

[3] Kohjiro Hara et al. Design of new coumarin dyes having thiophene moieties for highly efficient organic-dye-sensitized solar cell, New J. Chem. 27 (2003) 783-785.

[4] Amaresh Mishra et al. Metal-free organic dyes for dye-sensitized solar cells: From Structure: Property relationships to design rules, Chem. Int. Ed. 48. (2009) 2474-2499.

[5] He Zhao et al. Hydrazide-containing inhibitors of HIV-1 integrase, J. Med. Chem.40 (1997) 242-249.

[6] C. Kontogiorgis, D. Hadjipavlou, Biological evaluation of several coumarin derivatives designed as possible anti-inflammatory/antioxidant agents, J.Enzym.Inhib.Med.Chem. 18(2003)6369.

[7] J. Thipperudrappa, S.M. Hanagodimath, Fluorescence quenching of 1,4-bis [2-(2-methyl phenyl) ethenyl]-benzene by aniline in benzene-acetonitrile, International journal of Life science and Pharma research. 3 (2013).

[8] P. K Behera, A. K. Mishra, Static and dynamic model for 1-napthol fluorescence quenching by CC14 in dioxane-acetonitrile mixtures, J. Photochem. Photobiol. A: Chem. 7 (1993) 115-118.

[9] Haruo Schizuka, Toshio Saito and Toshifumi Morita, Fluorescence quenching of aromatic molecules by inorganic anions J. Chem. Phy. Lett. 56 (1978) 519-522.

[10] Roy.R and Mukherjee.S. Fluorescence quenching of carbozole and indole by Ethylenetrithiocarbonate, J. Chem. Phys. Lett., 140 (1987) 210-214.

[11] Murat Acar et al.The fluorescence quenching mechanism of coumarin120 with $\mathrm{CdS}$ nanoparticles in aqueous suspension, J. Luminescence, 157 (2015) 10-15.

[12] John Olmsted, Oxygen quenching of fluorescence of organic dye molecules, j. Chem. Phy. Lett. 26 (1974) 33-36,.

[13] J.S. Kadadevarmath et al. Static and dynamic model fluorescence quenching of laser dye by carbon tetrachloride in binary mixtures, Spectrochim. Acta Part A.17 (2014) 630-634.

[14] H.M. Suresh Kumar et al. Analysis of fluorescence quenching of new indole derivative, by J.Lumin. 116 (2006) 35-42.

[15] J. R. Mannekutla et al. Fluorescence quenching of UVITEX-OB by aniline in alcohols and Alkanes, Spectroscopy Letters. 39 (2006) 321-335.

[16] M. Basanagouda et al.Synthesis of some new 4-aryloxmethylcoumarins and examination of their antibacterial and antifungal activities, J. Chem. Sci. 121 (2009) 485-495.

[17] J.M. Frank, S.J. Wawilow, Sphere of action of the extinction phenomena in fluorescent Liquids, Z. Phys. 69 (1931)100-110.

[18] John T. Edward, Molecular volumes and the Stokes-Einstein equation, J. Chem. Edu.47(1970). [19] J. C. Andre, M. Niclause, W. R. Ware, Kinetics of partly diffusion controlled reactions I. Transient and apparent transient effect in fluorescence quenching, Chem. Phys. 28 (1978) 371.

[20] Zeng H, Durocher G, Analysis of fluorescence quenching in some antioxidants from nonlinear Stern-Volmer Plots, J. Lumin. 63 (1995) 75-84.

[21] J. Keizer, Non-equilibrium statistical thermodynamics and the effect of diffusion On chemical reaction rates, J. Phys. Chem. 86 (1982) 5052-5067.

[22] G.C. Joshi et al. Diffusion-controlled reactions: Transient effects in the fluorescence Quenching of indole and N-acetyl tryptophan amid in water, J. Phys. Chem. 94 (1990) 2908-2914. 